\title{
BRIEFINGS \\ Psychiatry in Sudan: a personal experience
}

\author{
Peter Hughes
}

I would like to describe my brief impressions of psychiatry in Khartoum, Sudan and raise some ethical issues that arose for me there.

I went to Sudan in January 1995 to accompany some colleagues to a conference on Development Aid for the Developing World. While there I took the opportunity to visit the various health services that are in the three cities that form Khartoum, the capital city of Sudan. I also had the privilege of seeing the psychiatry services.

I was well aware of the barrage of criticism that the Sudanese State elicits from both the Eastern and Western media. This was the pariah nation the terrorist state. In actual fact it appeared very different to me. I found a people of great warmth. kindness and tolerance. This formed the philosophy of the country in day to day life as well as the psychiatric services.

I found a desperately poor country wracked by endless civil war and famine. Politically Sudan steers an independent course which has not won it many friends. This has resulted not infrequently in loss of aid and outside support. In this environment the health services groan and creak serving its burgeoning population as well as massive numbers of refugees from neighbouring African countries and internal migration from South to North. Medicine and surgery predictably take a priority. However to my surprise I found a rich tradition of psychiatry in Sudan. The psychiatrists were erudite and sophisticated psychologically. They manage to work in the most difficult circumstances, acutely aware of high Western and Eastern standards yet struggling through the utmost deprivations to offer a decent service.

Khartoum appears to be the only real centre of psychiatry. Of note is the total lack of services in South Sudan. Most people initially see mental illness in a religious or mystical sense. This must be seen in the context of the strong Sufi Islamic movement throughout the country. Alternatively it is seen as a moral weakness particularly for females. Traditional healers may be consulted initially or one might attend one of the clinics that are attached to the mosques. There, both a religious viewpoint and a more traditional Western, psychiatric approach are available. Like many other African countries only the most severely unwell are brought for treatment. This is particularly true for females where mental ill health is a cause of great family shame. The great hospitals of Khartoum and Omdurman are thus a tertiary referral service to a great extent. The three main hospitals are very similar in appearance and function. The entrance to Omdurman hospital proclaims in the Arabic Quranic words that there is a cure for every illness which must be a great hope for family members of the patient. Another hospital evolved out of the prison system as the bars. locked doors and staff military uniforms testify. In spite of language difficulties I found no difficulties in diagnosing illnesses here-schizophrenia, mania, depression were overt. I believe the most common diagnoses however are organic e.g. delirium of malaria, epilepsy assoclated states. I was struck by the religious tolerance demonstrated by not only the staff in the hospitals but everyone I met in Sudan. There is a sizeable proportion of non-Muslim Southerners in the hospitals. I saw complete acceptance of them. complete religious tolerance. There was an occupational emphasis in the treatment regime. There were many programmes fostering new skills to facilitate integration of that patient into society. There is a strong religious approach with tranquillising. soothing Quranic recitation available to those who wish. I found the air of peace and brotherhood refreshing. The patients were warm and inquisitive as to who I was. One patient believed that I was a spy from Bosnial At all stages they showed grace and courtesy. The women's ward however was particularly harrowing. It is a great embarrassment in Sudanese society for a woman to be mentally unwell. They are brought to the wards when the family can literally contain them no longer. Their ward was neglected, filthy. The locked women's 


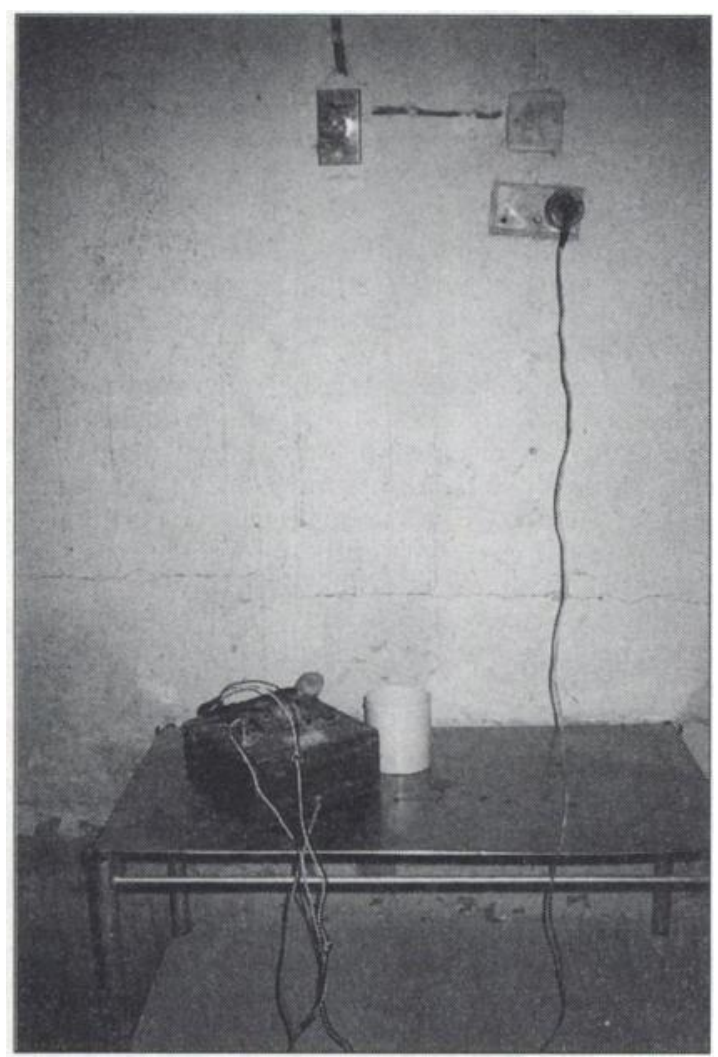

Fig. 1. ECT appliances used in Sudan

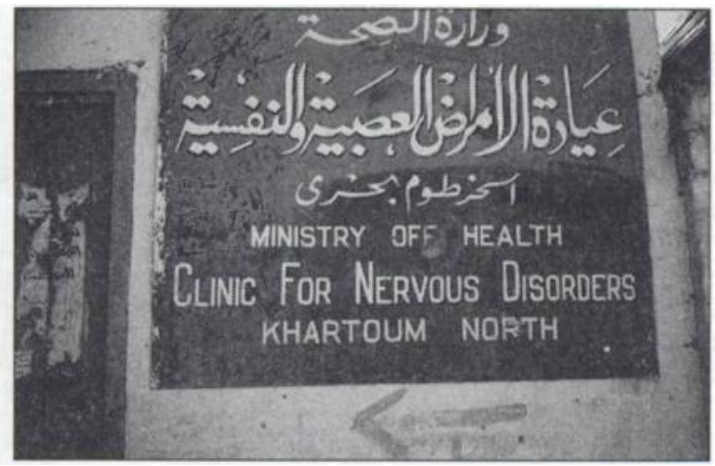

ward was simply a vision of Hell. I had not seen anything like this anywhere in Africa. Yet at the same time the staff were protective of the women and treated them with the greatest dignity in spite of the hellish circumstances.

My greatest surprise in Sudan was the treatment available or rather not available. Almost a firstline in the different hospitals I visited was unmodified electroconvulstve therapy (ECT). The psychiatrists were apologetic. They had simply no option. Psychiatric medicines are more expensive than others in Sudan. The hospitals cannot afford them, let alone the patients. I did witness patients immediately after unmodified ECT. They appeared to suffer no ill effect. However, broken bones are common. They told me that sometimes if someone is very anxious prior to treatment they are given some intravenous diazepam to relax them! Indications for ECT are naturally far more extenstve than in the UK. They included depression, mania, and schizophrenia. They assured me there that their results were very good although they would not have wished for this regime if they had any choice at all.

This is the ethical issue I wished to highlight. The psychiatrists there asked me as part of development aid work to try to donate ECT machines to Sudan where I know they will be used in a way that is shocking to us in the West. This is my dilemma, as well as the practical difficulties of getting these machines in UK. The machines I saw there are beyond belief with loose wiring and erratic current.

In spite of these great difficulties I was impressed by the eclectic approach to treatment - the use of religion in a healthy, tolerant way, community approaches that are developing. the spirit of brotherhood and sisterhood such as in the prayer when everyone is equal from the director of the hospital to the ill patient. I would be interested to hear views on ECT in the developing world context. I would of course welcome any practical help. I can easily organise transport of any medical equipment or psychiatric medication to where it is needed desperately.

Peter Hughes, Research Assistant/Honorary Senior Registrar in Psychiatry, Guy's Hospital, London 